\title{
A Dream or a Nightmare
}

I was born in Hong Kong. My parents and I migrated to Manchester, England when I was twelve. I was addicted to gambling from the time I was eighteen, for more than 25 years. I led a turbulent life filled with regrets and harms caused by excessive gambling. However, following a revelation, I managed to achieve total abstinence from gambling. This was the best thing that has ever happened to me. I am now an assistant minister at the Manchester Chinese Christian Church in England. Apart from preaching, I also provide support and help to problem gamblers and their families.

When I look back, my gambling addiction reflected the influence of family and friends. As is typical of many Chinese immigrants in the UK, my parents ran a catering business to make a living. They worked very hard during business hours but sought solace in casinos after work, or played mahjong at home. I often felt neglected and a sense of being unloved. Growing up in a family which favored gambling, I believed there was nothing wrong with the activity, and had never considered the potential negative repercussions. The adult gambling appeared to be having good fun.

As a young teen, I did not have the money to participate in gambling activities. At seventeen, my Chinese friends convinced me to gamble with an illegal bookmaker. Although I was skeptical at first, I gradually became very interested in the activity and truly believed that I had conceived a strategy for ensuring I would win. Not long after that, I was introduced to casino gambling and soon became very fond of baccarat. Ironically, my gambling parents discouraged me from playing. I challenged my parents' authority and started what they wanted me to stay away from.

I had a massive win at eighteen and got enough money to buy two detached houses. Due to my gambler's dream, basically an optimistic view that I could win more, I lost all my fortune as a consequence of this greed and ambition. Not long after this, on account of my accumulating gambling debts, I decided to venture to Germany for five years, to gain experience in the catering business. On my return to England, I got married at 26 with the intent of settling down and raising a family.

Family life was happy; yet at times I yearned for the excitement I derived from gambling. I resumed my old lifestyle of casino hopping and craved for gambling activities more than before. Casinos provided a place for relaxation and meeting my old friends. The catering business was prosperous, hence I could play for high stakes at the gambling tables. However, my rash and impulsive betting pattern led to frequent losses. I 
resorted to borrowing money from my friends to recoup my losses.

There was a lot of tension between me and my family. I always lied to conceal financial and gambling problems. I was once down to my last few pounds and even seriously considered selling my property. I was short-tempered and my family was always the outlet for my bad moods. Soon my family found me irritable and distressed at all hours. Strangely enough, I felt happier at the gambling table.

My wife and I always quarreled about money and the lack of time I had for my family. I argued with her trying to distract her from probing any further into my problems. I did not fulfill my role as a father and as the head of the family. I was effectively absent from important stages of my children's young lives.

My self-esteem was low. I tried to seek a sense of importance and self-worth at the tables, and maintained the 'macho' image associated with gambling. I slept very little after long hours of gambling, and grew terribly exhausted. I lost interest in my work, and was anxious about receiving phone calls from friends who would demand money back from outstanding debts. This culminated in an extremely stressful lifestyle which I managed to sustain for more than 18 years. I attempted to quit gambling but failed time after time.

My wife, who was a Christian, eventually identified a link between my gambling behavior, continual frustration, and lack of interest in my family. She tried to convince me of the benefits that religion would bring. I simply laughed at her. I was used to relying on myself to overcome difficulties. I did not need a god to help me. There were times when I had running streaks, but even the wealth amassed from gambling did not bring any joy. I felt empty inside, and was deeply unhappy with my life.

Then, my life changed in a single moment. One afternoon while I was taking a nap, I fell half-asleep and was tossing about to get a comfortable position. On rolling over, I saw a black shadow attempting to forcefully enter my body. I was petrified and quickly leapt out of the bed. I stood in a cold sweat and with adrenaline pumping through my body. The addiction was sustained not only by irrational reasoning, but it seemed to me, by an underlying cause, something far more sinister than I could comprehend at that moment. I began to recognize that gambling was detrimental to my family, my social relationships, my health and ultimately, my life. Regret and guilt over the suffering I had caused due to my selfish gambling ambitions quickly rose to the surface, resulting in a desire to 'break free'.

I grew inquisitive about Christianity. I attended a prayer meeting in which I made a confession. The attendees were non-judgmental. I was given unconditional support and tender loving care which I had been desperately seeking for a very long time. At the end of this meeting, I walked out as a Christian. For the first time, I felt the burden and bondage of gambling lifted from my shoulders. My faith enabled me to change, to regain control of my gambling behavior, to resume the power to determine my own destiny, and to rebuild relationships with my family. I kept a distance from my gambling friends and took a firm stand against gambling activities. I met new friends at the church.

Since then I have become a much happier person and my life is more fulfilled. I do not crave for gambling to fill my emptiness, or have to prove myself to anyone 
by winning at gambling. Pre-conceived ideas of manliness and social status no longer bother me. Life is more than possessions, wealth and 'face'. My physical health and psychological well-being have gradually improved. I spend more time with my family and non-gambling friends. I am a happy person, with a new found freedom to live a much fuller life than I had imagined before.

Not everyone will quit gambling in the same way as I did but it is definitely possible to change your gambling behavior, with proper help. It is important to speak to someone who cares and understands your gambling problems. My advice to others is to be honest and open up.

Gary Kwok Wah Wong Email: garykwwong2626@yahoo.co.uk 